\title{
Article \\ Inclusive Social Lettings Practice: Opportunities to Enhance Independent Living for Disabled People
}

\author{
Isobel Anderson *, Dianne-Dominique Theakstone and Julia Lawrence \\ Faculty of Social Sciences, University of Stirling, Stirling, FK9 4LA, Scotland; E-Mails: isobel.anderson@stir.ac.uk (I.A.), \\ d.d.theakstone2@stir.ac.uk (D.T.), julia.lawrence@stir.ac.uk (J.L.) \\ * Corresponding author
}

Submitted: 15 January 2020 | Accepted: 28 April 2020 | Published: 31 July 2020

\begin{abstract}
Appropriate housing is a key element of independent living for disabled people, yet research evidence confirms the continuing, often negative, impact of unsuitable housing on their lives. This article examines access to social rented housing as a route to independent living, through a study of lettings practice for accessible and adapted homes. Drawing on the social and social-relational models of disability, the study adopted a disabled-led, co-production approach. Qualitative research methods were used to compare social landlord practice and track home seeker/tenant experiences. While housing providers were proactive in reviewing policy and practice to better meet the housing needs of disabled people, there remained some 'distance' between landlord goals and applicant experiences. Disabled people's extended lived experience of inappropriate housing, while waiting for a more accessible home, impacted negatively on their quality of life and physical and mental health. Social lettings policies and practice were necessarily complex, but often difficult for applicants to understand. The complexity of disabled people's housing needs meant that the matching process for suitable housing was also complex, often requiring individualised solutions. Recommendations to improve practice include making better use of technology to improve data on accessible/adapted properties and applicant needs; flexibility in lettings practice to facilitate effective matches; and flexibility in fully recognising disabled people's housing and independent living needs. Social rented housing remains an important mechanism for achieving disabled people's independence. Explicit recognition of the social-relational interpretation of disability could deliver more inclusive lettings practice and achieve more sustainable tenancies.
\end{abstract}

\section{Keywords}

accessible housing; disabled people; inclusive lettings practice; independent living; social rented housing

\section{Issue}

This article is part of the issue "Home, Housing and Communities: Foundations for Inclusive Society" edited by Isobel Anderson (University of Stirling, UK), Vikki McCall (University of Stirling, UK) and Joe Finnerty (University College Cork, Ireland).

(C) 2020 by the authors; licensee Cogitatio (Lisbon, Portugal). This article is licensed under a Creative Commons Attribution 4.0 International License (CC BY).

\section{Introduction}

This thematic issue focuses on home, housing and community as foundations for an inclusive society. For disabled people, reasonable accommodation and community living are recognised under the United Nations Convention on the Rights of Persons with Disabilities (UN CPRD; United Nations, 2006) as crucial elements for independent living on an equal basis with others (Ferri, 2018; Šiška, Beadle-Brown, Káňová, \& Šumníková, 2018). In many countries, housing policy increasingly reflects the demographic trend of an aging population; an increasing number of disabled people; and the need to enshrine disabled people's rights to independent living across the life course (United Nations, 2006). In countries which have developed social rented housing, the 
sector represents an important resource offering disabled people appropriate accommodation and independent living in a community setting (Mackie, 2012). This article presents new findings from research in Scotland, where social rented housing let by local authorities and non-government housing associations, to eligible households at below-market rents, accounts for $23 \%$ of the total dwelling stock (Stephens, Perry, Wilcox, Williams, \& Young, 2019, p. 113, Table 17d).

In 2018 the population of Scotland was approximately 5.5 million (National Records of Scotland, 2018), with an estimated $22 \%$ of the population ( 1.1 million) reporting they were disabled (Equalities and Human Rights Commission [EHRC], 2018). The number of people over 75 years of age is projected to continue to increase, alongside the number of people with impairments due to long-term health conditions or frailty (Fitzpatrick, Lees, McDonald, \& Galani, 2018; Skidmore \& Davis, 2017). Consequently, the number of people using wheelchairs and other mobility devices will increase, mirroring international trends (Gell, Wallace, Lacroix, Mroz, \& Patel, 2015; O'Hare, Pryde, \& Gracey, 2013). Within the UK, housing policy and law is a matter devolved to the Scottish Parliament since its creation in 1999. This has led to some variation in housing law and policy across the UK, but the broad findings of this research are applicable across social rented housing settings.

In the UK, research to date has argued for a 'threepronged' approach to meeting disabled people's housing needs across tenures: development of new wheelchair standard homes for owner-occupiers and tenants; support for home adaptations across tenures; and efficient allocation of accessible and adaptable homes in the social rented sector (Fitzpatrick et al., 2018; Joseph, Perry, Watson, \& Vickery, 2010; Watson \& Joseph, 2012). The research reported here focused on the third strand, seeking to better understand the processes behind applying for and moving into social rented housing, from the perspectives of disabled people and housing providers. Section 2 critically reviews the research evidence on accessible housing in relation to the social and socialrelational models of disability, prior to setting out the research questions addressed. The research methods for the study are set out in Section 3 and the main findings in Section 4. Conclusions on inclusive lettings practice are presented in Section 5, with a discussion of the implications for achieving independent living for disabled people.

\section{Disability, Lived Experience and Access to Housing}

In this article, we use the term disabled people in line with affirmative language used by disabled-led organisations, emphasising the ways that society can disable/disempower individuals with impairments. The approach draws on Oliver's (1990) social model of disability which criticised medical assumptions that disability was a product of physical impairment that needed to be cured or managed. Rather, disability arose where structural barriers were considered to hinder the capacity of some individuals with impairments to fully participate in society. The Union of the Physically Impaired against Segregation (UPIAS) distinguished between impairment as "lacking part of or all of a limb, or having a defective limb, organ or mechanism of the body," whilst, disability denoted "the disadvantage or restriction of activity caused by a contemporary social organisation which takes no or little account of people who have...impairments and thus excludes them from participation in the mainstream of social activities" (UPIAS, 1976 , pp. 3-4). That is to say, people with impairments are disabled by social structures and physical environments which constrain their ability to lead their lives independently. However, we also recognise limitations of the social model of disability and criticisms which have been debated over the decades. Whilst there is an extensive literature on disability theory, we draw here on Thomas' (2004) discussion, which argued that a more social-relational approach to disability pre-dated the purely social model. Acknowledging the creativity of the conceptual shift from the medical to the social, Thomas argued that structural barriers did not explain all of the problems disabled people faced. 'Impairment effects' - the role of impairment and illness in restricting life experiences were also important. A social-relational model conceived disability in relation to the social relationships between those with and those without impairment in society, "between those socially constructed as problematically different because of a significant bodily and/or cognitive variation from the norm and those who meet the cultural criteria of embodied normality" (Thomas, 2004, p. 28).

Focusing on the housing pathways of younger disabled people, Mackie (2012) also responded to criticisms that the adoption of the social model by usercontrolled groups, particularly independent living centres (Barnes \& Roulston, 2005) focused too much on structural constraints and failed to deal adequately with impairment (Shakespeare \& Watson, 2002). Drawing on Clapham's (2002) housing pathways framework, Mackie emphasised the importance of examining the interaction between structure and agency in negotiating access to housing. Developed from social constructionism, Clapham's framework assumed that housing pathways were shaped by both agency and structure, and both should be considered in housing research (Clapham, 2002 , 2003). While social constructionism has been criticised as relativist and of limited use to policymakers and practitioners (Collin, 1997; Jacobs \& Manzi, 2000), Clapham's pathways approach has nonetheless been widely adopted in housing research, including the ways societal and individual influences interact to shape the housing experiences of disabled young people (Mackie, 2012).

Accepting the above caveats in relation to disability theory and housing, we use the term 'disabled' here 
to denote how society and the environment can render pan-impairment groups less able to live independently. The term impairment is used when referring to any difficulty in physical, mental or sensory functioning which people experience. Intellectual impairments (or learning disabilities) include reduced intellectual ability and difficulty with everyday tasks; the term 'mental disability' is similar, though it can include mental disorders, such as depression or schizophrenia. Locomotional/mobility impairment includes difficulty with walking or moving around (e.g., necessitating use of wheelchairs or walking aids, or extra time or support to move around). Sensory impairment refers to visual and/or hearing impairment.

Adapted housing refers to social rented properties which have been modified in some way to improve accessibility for an individual's specific housing needs. Accessible properties are those constructed to meet inclusive design or accessible standards, such as Housing for Varying Needs (Scottish Homes, 1998; Watson \& Joseph, 2012) or Lifetime Homes (Goodman, 2011). Accessibility can also refer to the degree to which information, a service or a device/product is available to people with different impairments. Lettings practice is the process for letting vacant properties to new tenants, including both allocations schemes and choice-based lettings. The key focus of this research was on the process of matching a suitable adapted/accessible social house to a disabled housing applicant. However, individual lettings are part of a broader process that encompasses applying for housing, matching to a suitable property, offers of a property and viewing, and settling into a new tenancy. The research findings reflect this interpretation of the lettings 'process,' encapsulating the notion of a 'housing pathway' (Clapham, 2002; Mackie, 2012) to independent living, although the research did not exclusively adopt a pathways approach.

The co-production approach to this research emphasised the involvement of disabled people, embracing an emancipatory perspective (Barnes \& Sheldon, 2007; Stone \& Priestley, 1996). Focusing on the lived experiences of disability, disabled people were accepted as experts on what must change to achieve independent living. Our approach included working with Peer Researchers and disabled persons organisations, as well as local housing provider mechanisms for service user involvement. Although Peer Researchers may require skills training for a research role, participatory research can highlight voices of groups overlooked by policymakers, provide historical and conceptual awareness of an issue, and create reflexivity among participants that can lead to individual or collective empowerment (McCartan, Schubotz, \& Murphy, 2012; Meakin \& Matthews, 2017; Pleace \& Mitchell, 2015).

Previous accounts of disabled people's lived experiences of housing in Scotland have identified system barriers to finding a suitable home including: waiting years for a suitable house or adaptation; delayed hospital discharge, or time in residential care due to lack of housing; being inappropriately discharged into an inaccessible home; and finding it impossible to find an accessible home to rent or buy (Independent Living in Scotland, 2017). These barriers largely reflected a lack of adapted/accessible housing and problems accessing information about housing availability. Such shortcomings in the housing system also placed additional costs on NHS and social care budgets. Living in inappropriate housing prevented disabled people from fully contributing to society and constrained their participation in the economic and social life of their communities. People with learning disabilities in Scotland were found to be more likely to live in social housing ( $52 \%$ compared with $21 \%$ of the population as a whole) and less likely to live in a home they or their family owned (39\% compared with $66 \%$ ), with a significant proportion living in an institutional setting (Ormston, Eunson, \& McAteer, 2017). Disabled people were also disproportionately affected by post-2010 UK Government austerity measures including restrictions to housing and disability benefits (Beatty \& Fothergill, 2018; Manji, 2018) introduced into what was already a complicated landscape of living situations from independent living, through supported living to residential care (Šiška et al., 2018).

Research by Satsangi et al. (2018) on disabled people's housing experiences identified key factors for successful independent living including suitable adaptations, feeling safe in a location, access to transport and services, family and community support, and freedom from harassment. Interviewees reported that suitable housing helped positively transform their wellbeing and economic prospects. Conversely, unsuitable housing situations increased the risk of accidents, led to stress and ill health, and imposed costs on health services. Lack of social support, financial constraints and anti-social behaviour from neighbours were also reported as harmful to participants' sense of wellbeing. Satsangi et al. (2018) contributed to the EHRC (2018) Housing Inquiry, which called for local authorities and registered social landlords to embed independent living principles into lettings policies for social housing, to ensure real choice and control for disabled people.

A substantial body of Scottish legislation and policy underpins strategies to meet the housing needs of disabled people, from the introduction of 'Housing for Varying Needs' (Scottish Homes, 1998) to the Scottish Government (2019) guidance on delivering more wheelchair accessible accommodation across all tenures (Anderson, Theakstone, Lawrence, \& Pemble, 2019, pp. 7-20). Nonetheless, research evidence and literature to date has confirmed the continuing, often negative, impact of unsuitable housing on the lives of disabled people (Anderson, Theakstone, Baird, \& Jago, 2017; Anderson et al., 2019). Analysis by Fitzpatrick et al. (2018) identified 87,340 households with a wheelchair user in Scotland (3.6\% of all households), of which 17,226 (19.1\% of all wheelchair user households) had unmet housing needs. New housing therefore needed 
to incorporate higher accessibility specifications while the social and financial benefits of home adaptations were also recognised (Heywood \& Turner, 2007; Powell et al., 2017). The Scottish Government's consultation on a 'Housing to 2040' vision included a commitment to increasing accessible and adapted homes (Chartered Institute of Housing, 2019).

Disabled people seeking to access social rented housing often require particular design or adaptation features. The process of matching applicants to suitable properties is a critical element in meeting the housing needs of disabled people which has received relatively little research attention. This study contributes new evidence by examining disabled people's lived experiences of the social housing application system, alongside social landlord lettings practices. The research built on a pilot study that designed and tested a co-production approach (Anderson et al., 2017), which was further developed to address the following research questions:

- How can social landlords achieve more effective routes to independent living for disabled people?

- What improvements to lettings policies and practices will deliver equal housing opportunity for disabled people?

- What support do disabled house seekers require in the social housing application and lettings processes?

- How can adapted and adaptable housing better enhance independent living?

\section{Research Method}

This study addressed the above questions by examining the systems for matching disabled home seekers to adapted and accessible social housing in order to provide robust evidence to improve lettings policy and practice. Importantly, disabled people co-produced the research and recommendations through a participatory partnership involving a social housing landlord, a disabled person's advice and support organisation, a disabled-led Project Advisory Group, Peer Researchers, and close collaboration with the participating local housing providers. Qualitative research methods were adopted to understand the processes and experiences behind the quantified need for accessible housing revealed by Fitzpatrick et al. (2018). The research received ethical approval from the University of Stirling and compared landlord practice and applicant/tenant experiences in three local authority areas in Scotland. These were chosen to provide a mix of urban and rural geographical areas and contrasting population sizes (two in the central belt of Scotland and the third in the North of Scotland). All three managed their own social rented housing stock and worked in partnership with housing associations in their areas. The experiences of, and outcomes for, disabled social housing applicants seeking a suitable home, were examined over the study period (2017-2019) enabling 'real-time' expe- riences to be captured. Within each local authority area, the following research methods were adopted:

- Contextual research on local lettings policy and practice.

- Semi-structured interviews tracking the experiences of a cohort of disabled home seekers/new tenants.

- Observations and discussions of lettings practice in the three local authority areas (focused group discussions).

- Feedback sessions in the three local authorities to discuss emerging findings with co-production stakeholders and build consensus on conclusions and recommendations through triangulation (combining analysis of different data sets and perspectives) to ensure the quality and rigour of the study outputs (Flick, 2007).

The research partners also recruited a disabled-led advisory group (12 participants) of self-identifying disabled people or carers with lived experience of the social housing system and professional/advocates with expertise in meeting disabled people's housing needs. The group met three times, contributing to the research design, reporting and recommendations. Some members also facilitated discussions in the local authority feedback sessions. Three self-identifying disabled Peer Researchers were recruited to assist with interviewing disabled home seekers/tenants. Each completed a training session covering fieldwork safety protocols, gaining informed consent and interview skills. Twenty-six out of the forty-three semistructured interviews (over two waves of fieldwork) were conducted by the Peer Researchers, with support from the research team. Most interviews took place in participants' homes. Where these were inaccessible for Peer Researchers, alternative locations, such as an accessible library or café were used, or a University Researcher conducted the interview.

\subsection{Tracking Experiences of Disabled Home Seekers and Tenants}

The study adopted a longitudinal approach to following the experiences of disabled people applying for social housing or who had recently moved into social housing, captured through qualitative semi-structured interviews in order to understand participant perspectives (Creswell, 2009). The target was to recruit up to ten participant households in each area, and to follow-up after 2-3 months and then up to one year from the first interview. Table 1 shows the characteristics of the 28 participant households successfully recruited for first interviews, all of which contained at least one disabled adult or child. Participants were split fairly evenly across the three local authority areas. Around one third of households (8) had recently moved into suitable social housing while the majority (20) were housing applicants seek- 
Table 1. Characteristics of participants at first interview ( $N=28$ households with at least one disabled person).

\begin{tabular}{lr}
\hline Local Authority of Residence & $\mathrm{N}$ \\
Local Authority Area & 8 \\
Local Authority 1 & 10 \\
Local Authority 2 & 10 \\
Local Authority 3 & 28 \\
Total & 28
\end{tabular}

\section{Housing Application/Lettings Status}

Status

New/recently housed tenants in suitable social rented housing (local authority or housing association) 8

Applicants seeking suitable social rented housing (all tenures, including seeking transfer from 20 unsuitable social rented housing) Total

\section{Housing Tenure}

Tenure

Social Rented (Local authority 14, Housing Association 2) 16

Privately Rented

Home Ownership

Tied Accommodation

Staying with Family

Total 28

Interviewee Status

Status

Interviewed alone

Total

ing suitable social rented housing. More than half of participants (16) were already living in the social rented housing sector (eight of these were suitably housed and eight were seeking a transfer to more suitable housing). Of the remaining 12 households, five were renting privately, four were homeowners, two lived in tied accommodation and one was sharing with family. In 19 households, one participant was interviewed alone while in the other nine cases two participants were interviewed together/as a couple.

Local housing providers identified potential disabled housing applicants and asked if they would like to take part in the study. Contact details for those interested were passed to the research team who provided additional information and gained informed consent. Recruitment proved a complex and lengthy process, with partners continuing to seek participants until recruitment targets were reached or the pool of potential participants was exhausted. The achieved sample of 28 was sufficient to provide depth of comparative analysis of experiences of different households, broadly attain- ing saturation in understanding (Dey, 1999). Disabled applicants/tenants who took part in initial interviews were contacted again by telephone two-three months later for an update on their housing situation (Table 2). Of the 28 initial interviewees, 22 (79\%) were successfully re-contacted, with just six not responding to an invitation by phone or a follow-up email. This proactive approach helped assess optimum timing for a second interview (Table 3 ).

Second semi-structured interviews were successfully conducted with 16 households $(73 \%$ of the 22 successful follow-up contacts, and $57 \%$ of the initial 28 interviewees). Second interviewees included one suitably housed tenant who had only lived in their property for two weeks at the time of the first interview, providing new information on their experience of their home. Second interviews were not appropriate for the other suitably housed first interviewees as they had already given full accounts of their experiences. Most second interviews (15 participants) were applicants still seeking suitable housing at the time of the first interview

Table 2. Outcome of follow-up contact ( $N=22$ successful contacts, $2-3$ months after first interview).

\begin{tabular}{lrr}
\hline Participant outcome & N & $\%$ \\
\hline Total first interviews & 28 & 100 \\
Successfully re-contacted by telephone call/email & 22 & 79 \\
No response to follow-up telephone call/email & 6 & 21 \\
\hline
\end{tabular}


Table 3. Housing application/lettings status of participants at second interview ( $N=15$ households, up to one year after first interview).

\begin{tabular}{lr}
\hline Status & $\mathrm{N}$ \\
\hline Tenant in suitable social rented housing (local authority or housing association) & 1 \\
Applicants seeking suitable social rented housing (all tenures, including seeking transfer from & 15 \\
$\quad$ unsuitable social rented housing) & 16 \\
Total Second Interviews & 6 \\
Second interview not appropriate after follow-up contact or participant withdrew & 73 \\
Total Second Interviews as percentage of successful follow-up contacts (16 out of 22) & 57 \\
Total Second Interviews as percentage of first interviewees (16 out of 28) & \\
\hline
\end{tabular}

and a small number withdrew because of health reasons or did not respond to further contact. Interviews were conducted face to face wherever possible and mostly lasted around 45 minutes. Discussions explored the processes of applying for housing, waiting for an offer, and accepting a tenancy. Some interviews touched upon stressful situations and interviewers were trained to respond sensitively, including pausing or ending an interview and providing contact information for support services. Participant pseudonyms were used in reporting to preserve anonymity.

\subsection{Local Context and Discussions of Lettings Practice}

The research design also included discussions of lettings practice in the three areas to ensure an accurate understanding of local policy and practice. Sessions were arranged by key contacts and informed consent was agreed with each participant. Four sessions were conducted, with between 2 and 9 people, in private meeting rooms. Discussions included housing professionals, occupational therapists and support staff workers and lasted 90-120 minutes. All discussions were audio-recorded and participants were allocated an identifier code to ensure anonymity in reporting (e.g., LA1, P2 refers to local authority 1 , participant 2). Participants in these sessions were also invited to the local feedback sessions.

\subsection{Local Authority Feedback Sessions}

Local authority feedback sessions were held to share emerging findings and offer an opportunity to respond to issues and help co-produce recommendations. Across the three areas, 60 participants attended these sessions, including Peer Researchers, advisory group members, housing and service providers, tenant group representatives and local organisations/individuals involved with disabled people's housing issues. All gave their informed consent to participate.

\subsection{Analysis and Reporting}

Topic guides for first and second interviews with disabled home seekers and tenants covered the following areas, as appropriate to the interviewee's housing situation:
- Past/present housing situations, location, household, property, length of stay, changes between interviews.

- Reasons for looking to move, needs for adapted housing, impairments, critical requirements.

- Experience of applying for housing, offers, moving to new accommodation, input to design or adaptations.

- Experiences of managing in inappropriate housing, time waiting.

- Understanding of systems, help received, suggestions for change, any further issues.

The topic guide for local authority lettings practice covered local policy, organisational structure, application and property databases, decision-making processes, matching applicants and vacant adapted/accessible homes, disabled people's participation, collaborative working and suggestions for change.

Interviews and discussions were digitally recorded and all data was analysed thematically to address the study research questions and triangulated across the different local contexts and perspectives of disabled home seekers, and housing providers to ensure quality and rigour (Flick, 2007). A thematic coding frame was developed drawing on the framework method for qualitative analysis (Ritchie \& Lewis, 2003). Due to the inaccessibility of qualitative software packages for visually impaired researchers, the team used Excel worksheets to manage the data analysis process. Researchers listened to the audio recordings and coded salient experiences and verbatim quotations under thematic headings, in line with the topic guide questions. A sample of coded interviews were cross-checked to ensure consistency and the team discussed patterns emerging from the data to ensure capture of all pertinent themes, in a format that could be tracked and was accessible for all researchers. Although resources constrained data collection to three case study areas (rather than a national study), the combination of data sets, systematic analysis, and co-produced developmental discussions resulted in a degree of consensus on the study findings and conclusions in which the research partners had considerable confidence. The following section presents the key research findings summarised from the thematic analysis. 


\section{Research Findings}

\subsection{Applying for Housing}

The three local authorities used different systems to assess and prioritise applicants including awarding 'points' for homelessness, sustainable communities, and applicants transferring within the landlord's stock. All three also had distinctive mechanisms for assessing needs for adapted and accessible housing. In one case, housing staff made the assessment as a matter of housing need (not a medical assessment). A second authority utilised 'Health and Housing Priority' forms, scrutinised by a panel, which included housing, social work and occupational therapy staff. In the third approach, if required, housing staff sought assistance from social work and health professionals. Importantly, none of the authorities requested medical practitioners to assess healthrelated housing need, recognising that where applicants were previously assessed for a medical condition, this did not always affect what sort of property they needed. Assessments were shifting towards establishing whether functional ability was affected by housing (for example, stairs that they were unable to use) and whether this could be improved in a more suitable property. Such moves to a social, or social-relational, model of housing needs assessment corresponded better with disability rights frameworks than prior, more medical, approaches. All three systems relied on staff knowledge of applicant needs and local properties to generate appropriate housing offers. Participants discussed competing pressures on the social rented housing system and it was recognised that not all vacancies could be adapted to meet the needs of disabled applicants. Accurate information was vital so that disabled people were offered a property that improved their current housing situation. While some applicants had to widen their choices of location from higher demand areas, the potential benefits of social rented housing were clearly articulated by applicants such as Tina.

Tina had lived in a 3-bedroom private rental house for seven years. Her two sons, aged in their twenties, were on the autistic spectrum and Tina herself required wheelchair accessible accommodation and was struggling to use the stairlift installed. Her youngest son had experienced anti-social behaviour in the area and Tina felt that a social tenancy would provide greater security and stronger rights for repairs to be carried out since their private rented property had dampness and other safety issues. As Tina explained:

I'd feel more secure in a Housing Association or Council house because you don't want the phone to go and our landlord wants his house back. And all of a sudden you become homeless and there's a rush to move. The anxiety of having perhaps 2 months to move, I'd feel more secure. (Tina, Housing Applicant)
Other opportunities to improve practice included more fully reflecting the overall needs of the household, notably where more than one individual had housing needs. Applicants also favoured having a single named contact to support them through the application process, and in two local authorities this was considered beneficial to the landlord, although the third considered it might be too resource intensive.

\subsection{Lettings: Matching Up Applicants and Vacancies}

Effective matching of disabled applicants to adapted/ accessible properties involved reletting vacant properties, recovery of properties no longer occupied by a disabled person, nominations to Registered Social Landlords, and letting newly built dwellings. To make best use of stock, social landlords require a comprehensive audit of property adaptations and potential to be adapted. This ideal was not always available and such data could be routinely collected during property visits to better inform planning for accessible housing. Participants in all three areas discussed the potential effectiveness of new technologies in facilitating up-todate information on tenants' needs and property characteristics in order to achieve more effective matches. Different methods of procurement of new build housing appeared to result in different standards of specification and therefore of adaptability and accessibility of homes for disabled people. Practitioners also discussed the housing management conflict between minimising rent lost on vacant properties, and acknowledging the extra time needed to match disabled applicants to suitable homes. In one local authority, pre-approval of required adaptions removed some of the delay in re-letting an adaptable home and the case was also made for flexibility in target letting times for adapted or accessibly designed vacancies, as illustrated in the following quotes:

The problem that we sometimes have is that we have a fully adapted house, but nobody wants to live there. It depends on the area. We've had a situation where five or six people on our waiting list have been offered a property-the house is suitable for all their needs, but it is not in the area that they want. Sometimes we end up letting adapted houses to somebody who does not need one because we have to get the house allocated. (LA3, P4)

It's common sense really. If there are good transport links, health centre, shops, schools and all the amenities that folk want....We have some rural areas that have few facilities, so they are in lower demand. But usually we can come up with something. (LA1, P2)

We're lucky because we still work a points-based system, so it is quite easy to pull up a mock list for another area to have a look to see if there is anybody 
waiting, so if the housing officer was off that day there are ways around having a look. (LA2, P1)

\subsection{Offers and Viewings}

A high proportion of participant home seekers received inappropriate housing offers, or no offers at all, during the tracking study. Of the 28 first interview participants, only two accepted an offer of suitable housing in the study period. Interview evidence indicated strongly that disabled people's extended lived experience of inappropriate housing had a negative impact on health and wellbeing. For example, a number of participants were effectively confined to just one or two rooms within their home for feeding, bathing, toileting, sleeping and socialising. Access to more rooms was sometimes at a cost, such as risk of falls or climbing stairs they could not safely manage. Even adaptations, such as a stairlift did not always 'fix' the problem, with one participant daily enduring numerous transfers between wheelchairs and stairlift to access the toilet, leaving her exhausted and meaning wounds relating to kidney dialysis took longer to heal. Other disabled applicants who remained without an offer of a suitable accessible/adapted house over a significant period indicated that they experienced emotional and mental distress.

Practitioners highlighted that up-to-date property information helped minimise unsuitable offers, saving scarce housing resources and preventing unnecessary frustration for disabled applicants. Participants advocated that assessment of the suitability of an adapted/accessible property should include the external environment and local support networks, as well as the physical access and internal features. Some disabled interviewees argued that access to a garden also should be recognised as key to emotional and mental wellbeing. Practitioners and applicants highlighted the need to proactively manage housing applications with more frequent reviews, especially where there had been no offer of suitable housing for 6-8 months. This could reassure those in need and enhance the accuracy of information held on housing applications. George and Gayle's experience illustrated some of the complexities in considering an offer of housing:

When George [tenant] came to view his adapted bungalow, he was unable to get inside with his wheelchair since there was a step at the front door. He had to look through windows and discuss what adaptations were necessary for him to be able to move in. George and Gayle accepted the keys with a list of adaptations still required, including widening doorways, cooker installation, an accessible bathroom and an accessible front path, but experienced a lack of coordination during the installation of these adaptations. They planned to make a pathway around the side of the property so that George could enjoy wheelchair access to the back garden, but this was not deemed a housing need by the housing provider and not included on their list of home adaptations. The couple also felt pressurised to carry out redecorating without assistance. They were informed that someone would check how the redecoration allowance had been spent. George pointed out that he would need longer as a wheelchair user who required assistance with painting tasks around the property.

A potential area identified for improved practice was the use of new technologies to provide virtual property viewings for disabled applicants unable to attend due to health or accessibility reasons. Local authorities could also make more effective use of nominations to suitable housing association properties and all social landlords could develop mechanisms to seek nominations from other providers where they had an adapted/accessible vacancy but no suitable applicant. This could be extended to seeking nominations from hospital discharge units and third-sector organisations (including from outside of the local area). Additionally, support could be provided to help disabled housing applicants navigate the schemes to arrange a home swap.

\subsection{Moving in and Making a Home}

Some disabled tenants needed support to move into and sustain their tenancies. This could be achieved by social housing providers ensuring tenancy sustainment strategies were inclusive of disabled people, empowering them to make a new tenancy into a sustainable home. However, effective lettings could prove transformative for disabled people, with participants emphasising the social and emotional benefits they gained from moving to a suitable accessible/adapted property:

I can do the dishes now, cook, move unaided around the house-and I'm rediscovering my relationship with my husband, whose stress is reduced by having fewer caring tasks. (Sam, New Tenant)

Inclusive practice can also involve disabled people in strategic approaches to the provision of accessible social housing and communities. There was a considerable consensus that the construction of newly built accessible and adaptable properties provided significantly greater scope to meet housing needs, compared to adaptation of older housing stock:

In LA2, two double storey houses were identified at the design stage of a new development as being suitable for a large family that were unlikely to be housed in existing Council stock. The properties were converted into one seven-bedroom house for the family which included adult twins who had complex needs that meant that they needed their own bedrooms. The mother believed a younger son also showed signs of having additional needs. The twins required major 
adaptations in their bedrooms, including the floors being reinforced, smooth fittings, integrated blinds and specially designed windows and wall finishing and a wetroom for easier bathing. The conversion was designed to be reversible (to two properties) if household needs changed in the future.

This was quite an extreme case and there were lots of professionals involved saying what was required to meet this family's needs-we had looked for years to find suitable housing for them and had not come up with anything. (LA2, P4)

\section{Conclusion}

Overall, our study showed that that while housing providers were proactive in reviewing policy and practice to better meet the housing needs of disabled people, there remained some 'distance' between landlord goals and applicant experiences. Thomas' (2004) socialrelational model of disability aided interpretation of the ways in which disabled people's extended lived experience of inappropriate housing exacerbated impairment effects on their daily lives. The length of time some disabled people spent waiting for more suitable housing was associated with long-term negative impacts on their physical and mental well-being. Equally, a move to appropriate housing could very significantly enhance independent living. The housing profession could draw on the social-relational model of recognising impairment ef- fects, to design more inclusive lettings practice where the experiences of disabled people inform housing solutions. Lettings processes remain complex and often difficult for disabled people to understand. Depending on their impairments, disabled people needed support with the application, viewing and moving-in processes, as did new tenants in Garnham and Rolfe's (2019) study of housing provided through social enterprise. The complexity of disabled people's housing needs meant that the matching process for suitable adapted or accessible housing was also complex. What worked for one household or property may not work for another-so there was often a need for quite individualised solutions. Nevertheless, a number of broad recommendations for policy and practice emerged from the study (Box 1).

Implementing these recommendations could speed up access to housing and facilitate more sustainable tenancies. Lettings systems should recognise the needs of all household members and the importance of the external environment as well as housing design for disabled people's wellbeing. Adaptations can make some older housing stock more liveable for some disabled people, but newly built accessible housing offers significantly more potential to appropriately meet complex mobility and other impairment related housing needs. The research identified housing solutions which maximised choice and control and enabled more disabled people to live independently, while also delivering more cost-effective lettings. As well as developing more inclusive lettings practice, our research recognised the importance of a na-

Box 1. Key recommendations for housing policy and practice emerging from the research.

1. Recognise that lettings periods for accessible/adapted social housing may require additional time to achieve an effective match and carry out necessary adaptations before an applicant is able to move in.

2. Where a vacancy cannot be matched to one of their disabled applicants, landlords should canvas widely for nominations among disability organisations and housing providers in and beyond the local area.

3. Improve involvement of disabled people by establishing local co-production groups in order to inform decisions on housing and its interconnections with independent living.

4. Explore the use of new technology to improve intelligence on adapted/accessible properties and to enable remote viewing for applicants who are unable to visit in person.

5. Recognise wider housing-related needs of disabled people, for example, access to a garden, public transport, and services such as retaining the same GP.

6. Review allocations systems to ensure that applicants who make some 'liveability' improvements to their homes while waiting for an accessible property are not disadvantaged in lettings schemes.

7. Develop peer support networks where a disabled tenant who has experienced the lettings process can support disabled home seekers.

8. Ensure local housing need assessments include targets that are proportional to the amount of new accessible/adapted housing required across tenures.

9. Develop minimum accessibility standards for new build social housing so that it is more economical and easier to adapt in the future. 
tional strategy to improve the provision of accessible homes to meet the needs of disabled people with a wide range of impairments. Design standards ideally should meet universal design and full wheelchair access within mainstream housing (Centre for Excellence in Universal Design, 2020), so that disabled people and their families have equal housing opportunities and the human right to an accessible home in an accessible and sustainable community. Different methods of procurement of new build housing appeared to result in different standards of specification and therefore of adaptability and accessibility of homes for disabled people. This could be addressed as an equalities issue in commissioning procedures drawing on Scottish Government (2019) guidance on increasing wheelchair accessible housing. Participants also recognised competing pressures on the social rented housing system, such as the needs of homeless people (Anderson, 2019), necessitating a national strategy which is inclusive of differing groups facing housing exclusion.

Our research findings on social lettings practice have reinforced those of other recent studies (EHRC, 2018; Ferri, 2018; Independent Living in Scotland, 2017; Satsangi et al., 2018; Šiška et al., 2018) which acknowledged progress, but not sufficient progress, towards independent living for disabled people. Šiška et al.'s (2018) international study demonstrated the challenges of evidence gathering and meeting the goal of community living for disabled people. Similarly, Ferri's study of Article 2 of the CRPD, on reasonable accommodation, duty to remove barriers "as an individualised response to the particular needs of an individual with disabilities to ensure equal opportunities" (Ferri, 2018, p. 48; emphasis added by Ferri) indicated there was still "a long way to go before the cross-cutting application of reasonable accommodation can be assured in practice." These findings were mirrored in this study of accessible social housing lettings, with disabled people continuing to experience lengthy periods of living in inappropriate homes despite some progress in seeking to improve supply and lettings practice. Our study identified a progressive shift in practice towards a social model of disability. However, it is recognised that organisational structures and individual practitioners may accommodate impairment and disability, but still hold a medical view of their causes. An explicitly social-relational approach (recognising impairment effects and structural barriers) might further enhance outcomes. Adopting the findings and recommendations from this study could deliver a more inclusive lettings practice offering significant opportunities to develop more effective routes to independent living. Inclusive design and lettings practice may not overcome all impairment effects faced by disabled people, but a social-relational practice which builds on the empowerment of disabled people and the positive practice of housing providers can make a significant difference in overcoming environmental structural barriers to independent living.

\section{Acknowledgments}

The authors gratefully acknowledge the project funders, DRILL (Disability Research for Independent Living and Learning) and the Big Lottery Fund. We wish to sincerely thank our key partners Horizon Housing Association and Housing Options Scotland, our Peer Researchers and our Project Advisory Group who contributed significantly to the study and provided valuable insights throughout the project. Our research participant organisations and individuals are not identified, but we are extremely grateful for their generosity of time and resources. We were privileged to be entrusted with private, and sometimes sensitive information, without which the research would not have been possible.

\section{Conflict of Interests}

The authors declare no conflict of interests.

\section{References}

Anderson, I. (2019). Delivering the right to housing? Why Scotland still needs an ending homelessness action plan. European Journal of Homelessness, 13(2), 131-159.

Anderson, I., Theakstone, D., Baird, C., \& Jago, L. (2017). Matching up? A pilot study of effectiveness of letting adapted social housing. Livingston: Horizon Housing Association.

Anderson, I., Theakstone, D., Lawrence, J., \& Pemble, C. (2019). Match me: What works for adapted social housing lettings? Action research to enhance independent living for disabled people. Edinburgh: Housing Options Scotland.

Barnes, C., \& Roulston, A. (2005). Work is a four letter word: Disability, work and welfare. In A. Roulston \& C. Barnes (Eds.), Working futures: Disabled people, policy and social inclusion (pp. 315-327). Bristol: The Policy Press.

Barnes, C., \& Sheldon, A. (2007). 'Emancipatory' disability research and special education needs. In L. Florian (Ed.), The Sage handbook of special education (pp. 233-246). London: Sage.

Beatty, C., \& Fothergill, S. (2018). Welfare reform in the UK 2010-16: Expectations, outcomes and local impacts. Social Policy and Administration, 52(5), 950-968.

Centre for Excellence in Universal Design. (2020). National disability authority, Dublin, Ireland. Universal Design. Retrieved from http://universaldesign.ie/ Home

Chartered Institute of Housing. (2019). Housing as a human right: Scottish housing day paper. Edinburgh: Chartered Institute of Housing Scotland. Retrieved from http://www.cih.org/resources/PDF/ Scotland\%2520Policy\%2520Pdfs/Scottish\%2520 Housing\%2520Day/scottish-housing-day\%2520 
paper\%2520FINAL.pdf

Clapham, D. (2002). Housing pathways: A postmodern analytical framework. Housing, Theory and Society, 19(2), 57-68.

Clapham, D. (2003). A pathways approach to homelessness research. Journal of Community and Applied Social Psychology, 13(2), 119-127.

Collin, F. (1997). Social reality. London: Routledge.

Creswell, J. (2009). Research design: Qualitative, quantitative, and mixed methods approaches (3rd ed.). Thousand Oaks, CA: Sage.

Dey, I. (1999). Grounding grounded theory: A guide to qualitative inquiry. London: Academic Press.

Equalities and Human Rights Commission. (2018). Housing and disabled people: Britain's hidden crisis. Equalities and Human Rights. Retrieved from https://www.equalityhumanrights.com/en/ publication-download/housing-and-disabledpeople-britains-hidden-crisis

Ferri, D. (2018). Reasonable accommodation as a gateway to the equal enjoyment of human rights: From New York to Strasbourg. Social Inclusion, 6(1), 40-50.

Fitzpatrick, J., Lees, F., McDonald, E., \& Galani, E. (2018). Still minding the step? A new estimation of the housing needs of wheelchair users in Scotland. Livingston: Horizon Housing Association.

Flick, U. (2007). Managing quality in qualitative research. London: SAGE.

Garnham, L., \& Rolfe, S. (2019). Housing as a social determinant of health: Evidence from the housing through social enterprise study. Stirling and Glasgow: University of Stirling and Glasgow Centre for Population Health. Retrieved from https://www.gcph.co. uk/assets/0000/7295/Housing_through_social_ enterprise_WEB.pdf

Gell, N. M., Wallace, R. B., Lacroix, A. Z., Mroz, T. M., \& Patel, K. V. (2015). Mobility device use in older adults and incidence of falls and worry about falling: Findings from the 2011-2012 national health and aging trends study. Journal of the American Geriatrics Society, 63(5), 853-859.

Goodman, C. (2011). Lifetime homes design guide. Watford: IHS BRE Press.

Heywood, F., \& Turner, L. (2007). Better outcomes, lower costs. London: Office for Disability Issues.

Independent Living in Scotland. (2017). We say: Our place, our space. The evidence on disabled people's housing issues (Scotland's Disabled People's Summit Report). Independent Living in Scotland. Retrieved from http://inclusionscotland.org/launchedour-space-our-place

Jacobs, K., \& Manzi, T. (2000). Evaluating the social constructionist paradigm in housing research. Housing, Theory and Society, 17, 35-42.

Joseph, G., Perry, A., Watson, L., \& Vickery, L. (2010). Mind the step: An estimation of housing need among wheelchair users in England. London: Habinteg.

Mackie, P. (2012). Housing pathways of disabled young people: Evidence for policy and practice. Housing Studies, 27(6), 805-821.

Manji, K. (2018). 'It was clear from the start that [SDS] was about a cost cutting agenda': Exploring disabled people's early experiences of the introduction of SelfDirected Support in Scotland. Disability \& Society, 33(9).

McCartan, C., Schubotz, D., \& Murphy, J. (2012). The self-conscious researcher: Post-modern perspectives of participatory research with young people. Forum Qualitative Sozialforschung/Forum: Qualitative Social Research, 13(1).

Meakin, B., \& Matthews, J. (2017). Improving understanding of service user involvement and identity: A guide for disabled people who are interested in being a service user representative. London: Shaping Our Lives.

National Records of Scotland. (2018). Mid-year population estimates Scotland, mid-2017. Edinburgh: National Records of Scotland.

O'Hare, M. P., Pryde, S. J., \& Gracey, J. H. (2013). A systematic review of the evidence for the provision of walking frames for older people. Physical Therapy Reviews, 18(1), 1-23.

Oliver, M. (1990). The politics of disablement. Basingstoke: MacMillan.

Ormston, R., Eunson, J., \& McAteer, G. (2017). Improving outcomes for people with learning disabilities: Opportunities and challenges for housing. Key findings and recommendations. Glasgow: Scottish Commission for Learning Disability.

Pleace, N., \& Mitchell, W. (2015). Education and training in housing related support: The extent of continuing vocational education and training in integrated housing and support in the EU. York: University of York.

Powell, J., Mackintosh, S., Bird, E., Ige, J., Garrett, H., \& Roys, M. (2017). The role of home adaptations in improving later life. Technical Report. London: Centre for Ageing Better. Retrieved from http://eprints.uwe. ac.uk/33945

Ritchie, J., \& Lewis, J. (2003). Qualitative research practice: A guide for social science students and researchers. London: Sage.

Satsangi, M., Theakstone, D., Matthews, P., Lawrence, J., Rummery, K., Mackintosh, S., . . . Boniface, G. (2018). The housing experiences of disabled people in Britain. Manchester: Equality and Human Rights Commission.

Scottish Government. (2019). Scottish Government guidance to local authorities and RSLs to support the delivery of more wheelchair accessible homes across all tenures. Edinburgh: Scottish Government.

Scottish Homes. (1998). Housing for varying needs. A design guide. Edinburgh: Scottish Homes.

Shakespeare, T., \& Watson, N. (2002). The social model of disability: An outdated ideology? Research in Social Science and Disability, 2, 9-28.

Šiška, J., Beadle-Brown, J., Káňová, S., \& Šumníková, P. 
(2018). Social inclusion through community living: Current situation, advances and gaps in policy, practice and research. Social Inclusion, 6(1), 94-109.

Skidmore, C., \& Davis, S. (2017). We must improve housing options for older and disabled people. Housing Learning and Improvement Network. Retrieved from https://www.housinglin.org.uk/blogs/We-mustimprove-housing-options-for-older-and-disabledpeople

Stephens, M., Perry, J., Wilcox, S., Williams, P., \& Young, G. (Eds.). (2019). UK housing review 2019. Coventry: Chartered Institute of Housing.

Stone, E., \& Priestley, M. (1996). Parasites, pawns and partners: Disability research and the role of nondisabled researchers. British Journal of Sociology,
47(4). 699-716.

Thomas, C. (2004). Rescuing a social relational understanding of disability. Scandinavian Journal of Disability Research, 6(1), 22-36.

United Nations. (2006). Convention on the rights of persons with disabilities (General Assembly Session 61, Resolution 106. A/RES/61/106 13). New York, NY: United Nations. Retrieved from http://www.un.org/ ga/search/view_doc.asp?symbol=A/RES/61/106

Union of the Physically Impaired against Segregation. (1976). Founding principles of the social model of disability. London: UPIAS.

Watson, L., \& Joseph, G. (2012). Mind the step: An estimation of housing need among wheelchair users in Scotland. Livingston: Horizon Housing Association.

\section{About the Authors}

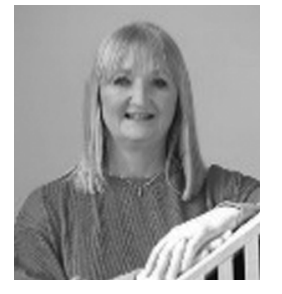

Isobel Anderson co-leads the Home, Housing and Community Research Programme at the University of Stirling. She has held more than 40 research awards and published widely for scholarly and practice audiences. Within the European Network for Housing Research (ENHR) Isobel has jointly co-ordinated two working groups: Welfare Policy, Homelessness and Social Exclusion (WELPHASE), 2004-2013, and Housing in Developing Countries, 2015-to date. She is on the international advisory committee of the European Journal of Homelessness.

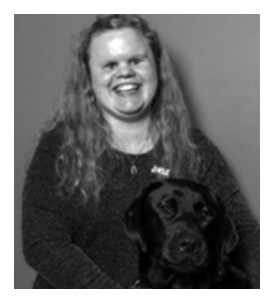

Dianne-Dominique Theakstone (PhD) graduated, along with her four-year-old black lab guide dog Merlin, with a PhD in Applied Social Sciences from the University of Stirling in 2018. She has over five years' experience of conducting co-production research; examples include: My Support My Choice: Users Experiences of Self-directed Support in Scotland (2020), Match Me: What Works for Effective Lettings of Accessible/Adapted Social Housing in Scotland (2019) and Online Guide for Disabled House Seekers Living in Great Britain (2018).

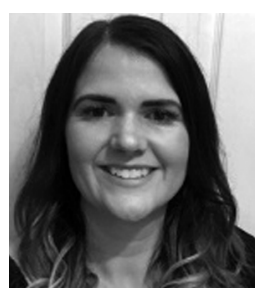

Julia Lawrence (Faculty of Social Sciences, University of Stirling) has recently finished work on two large research projects working in co-production with disabled people. These projects explored the allocation of adapted and accessibly designed social housing for disabled house seekers/tenants and Self-directed Support (social care). She has experience of using a mixed methodological approach, including semi-structured interviews, stakeholder focus groups and questionnaires, and supporting the needs of disabled people working as Peer Researchers. 